\title{
INFECÇÃO PULMONAR FATAL POR LAGOCHILASCARIS SP., PROVAVELMENTE LAGOCHILASCARIS MINOR LEIPER, 1909
}

Mário A. P. MORAES (1), Maria Vanda Catão ARNAUD (2), Roberto Cavalleìro de MaGEDO (2) e Antônio Ernesto ANGLADA (2)

\begin{abstract}
R E S U M O
$\mathrm{E}$ descrito um caso fatal de infeç̧ão por Lagochilascaris sp., - provavelmente Lagochilascaris minor Leiper, 1909 -, com localização pulmonar. O pa. ciente, do sexo feminino, oriundo de Curralinho-Estado do Pará, desenvolveu uma pneumonite grave, que the acarretou a morte, por insuficiência respiratória, em pouco menos de três meses. À autópsia, numerosas lesões de natureza exsudativa e granulomatosa podiam ser vistas em ambos os pulmões, indicando tuberculose ou infecção micótica pulmonar. Todavia, quando se procedeu ao exame microscópico, ovos, larvas e até uma fêmea grávida do verme foram encontrados nos tecidos, como causa da doença - sempre no interior de granulomas ou de extensas áreas de necrose. Em quase todos os casos, até agora conhecidos, de lagoquilascariase humana - cerca de 25 -, o parasito se localizava nos tecidos do pescoço, nos seios da face ou sobre a apófise mastóide. Neste caso, pela pri. meira vez, um representante do gênero Lagochilascaris é referido em sitio bem distinto do habitual, no hospedeiro humano. O achado, por outro lado, dos diferentes estádios evolutivos do helminto, dispersos pelo parênquima pulmonar, além de mostrar a natureza errática do parasitismo, sugere fortemente a existência de um ciclo pulmonar na lagoquilascaríase humana.
\end{abstract}

\section{N T R O D U G Ã O}

A infecção humana por Lagochilascaris minor, embora rara, tem crescido bastante em frequiência, nos últimos anos, em nosso País, principalmente nas regiões Norte e Centro-Oeste - resultađo, por certo, de uma divulgação maior dos aspectos da lagoquilascaríase, entre clínicos a patologistas, a partir do trabalho de ARTIGAS \& col.1. Quase todos os casos descritos por Autores brasileiros apresentavam em comum lesōes supurativas no pescoço ou sobre a apófise mastóide 1,6,7,11,13. Fora do Brasil, a mesma localização tem sido também encontrada $3,8,12,14,15,16,17,18,21,22,23$, fato que levou SPRENT 20 a sugerir para o verme - considerado desde sua descoberta, por LEIPER ${ }^{12}$, como parasito errático no homem - um ciclo evolutivo passando pélo pulmão e terminando nos tecidos do pescoço ou zonas circunvizinhas; para atingi-los, as larvas do $3 .^{\circ}$ estádio, uma vez transposta a glote, a invés de serem deglutidas, atravessariam a parede do nasofaringe $\mathrm{e}$ as amígdalas, em direção à pele, não sendo ainda claras as razões desse trajeto anômalo na espécie humana. O hospedeiro natural definitivo de L. minor permanece, até hoje, desco. nhecido.

Ao todo, existem publicados 17 casos de lagoquilascaríase humana, sendo 6 do Brasil 1,6. $7,11,13,5$ de Trindade e Tobago 8,12,17,18, 4 do Suriname 15,16,21,23, 1 da Venezuela 22 e 1 da Costa Rica 3. Na literatura nacional, entretanto, há indicaçōes sobre mais 7 casos $2,5,9,19$, referidos

(1) Universidade de Brasília, FS/MDC, Brasilia - DF, Brasil

(2) Instituto Ofir Loiola, Belém-Pará, Brasil 
MORAES, M. A. P.; ARNAUD, M. V. C.; MACEDO, R. C. de \& ANGLADA, A. E. - Infecção pulmonar fatal por Lago. chilascaris sp., provavelmente Lagochilascaris minor Leiper, 1909. Rev. Inst. Med. trop. São Paulo 27:46-52, 1985.

somente em Congressos, o que dá para o Brasil um total de 13 pacientes já descobertos. Da mesma forma, um outro caso, nunca publicado, procedente do Suriname, foi exposto por NAS SY 14 a um Congresso de Otolaringologia, em Caracas, e citado, três anos mais tarde, por BRUIJNING ${ }^{4}$. Esta citação, aliás, tem induzido diversos Autores a considerá-lo como pertencente a Bruijning.

Neste trabalho é descrito o desenvolvimento de um verme do gênero Lagochilascaris muito provavelmente Lagochilascaris minor nos pulmöes de paciente oriunda do Estado do Pará, causando uma pneumonite fatal, com duração de apenas algumas semanas. Dita localização - no parênquima pulmonar -- nunca antes havia sido registrada, e tal como em caso anterior ${ }^{13}$, observado pelos dois primeiros Autores, de lagoquilascaríase cervical, foi possível também demonstrar-se a evolução do helminto, desde o ovo até a fase adulta, nos tecidos do hospedeiro.

\section{APRESENTAGÃO DO CASO}

A paciente, M.F.F.B., de 18 anos, cor parda, solteira, procedente de Curralinho - na Ilha de Marajó, buscou o Hospital do Instituto Ofir Loiola, em Belém-Pará, no dia 16 de junho de 1983. com a queixa de febre e dificuldade res. piratória, distúrbios que lhes haviam surgido cerca de quatro ou cinco semanas antes. Seu estado geral era precário e como, durante a fase de atendimento, o transtorno respiratório se agravasse, evoluindo para cianose, resolveuse admiti-la em situação de emergência. No dia seguinte, menos opressa, foi ela submetida a diversos exames, dentre os quais uma radiografia do tórax, que revelou "lesões pređominantemente exsudativas em ambos os pulmões, mais extensas à direita". A pesquisa de BAAR e fungos no escarro, entretanto, resultou negativa, apesar de repetida várias vezes, inclusive mais tarde, em datas diferentes. No hemograma havia as seguintes alterações: anemia, leucopênia, linfocitose relativa e aneosinofilia.

A despeito da medicação instituída - à base de antibióticos e quimioterápicos -, a doente não melhorou; prosseguiu pálida e abatida, com tosse, expectoração abundante, febre des. contínua, dispnéia e, por vezes, cianose. Em
30 de junho, devido a suspeita de tumor da laringe, levantada pelo aparecimento de forte rouquidão, realizou-se uma laringoscopia seguida de biópsia. O exame histopatológico dos cortes mostrou a existência apenas de um processo inflamatório inespecífico. Esses cortes foram depois revistos e nenhum parasito pôde ser neles encontrado. Infelizmente, a doença, por falta de diagnóstico, continuou a se agravar e, em 12 de julho, a paciente exibiu edema da região cervical e dos membros inferiores. Algumas horas depois, entrou ela em grande agitação; a dispnéia e a cianose tornaram-se então mais intensas e, finalmente, veio a doente a falecer na madrugada do dia 13 de julho. Ao exame cadavérico, levado a cabo no mesmo dia, constatou-se um corpo em estado caquético, sem maiores alterações no hábito externo a não ser o edema antes referido. Quanto ao hábito interno, lesões macroscópicas importantes existiam apenas no sistema respiratório, a saber: a) mucosa das vias aéreas extrapulmonares entumescida e recoberta por ex sudato espesso em toda sua extensão; b) pleuras viscerais mostrando pontilhado difuso, saliente e de cor amarela e c) pulmôes distendidos e de consistência firme, pela presença, em seu interior, de numerosas áreas de consolidação; a superfície de corte, quando exposta, revelou semeadura extensa de focos de broncopneumonia, entremeados por lesões redondas, pequenas (2 a $3 \mathrm{~mm}$ de diâmetro) e também amarelas. Além disso, vários linfonodos hilares, peribrônquicos e mediastínicos estavam aumentados, medindo os maiores cerca de $1,5 \mathrm{x}$ $1,0 \mathrm{~cm}$. Como causa da morte inscreveu-se insuficiência respiratória, devida a doença granulomatosa pulmonar, provavelmente tuberculose miliar ou infecção fúngica. Surpreendentemente, o exame microscópico revelou a existência, nos cortes pulmonares, de inúmeras secçóes de vermes redondos, ocupando o centro de estruturas granulomatosas ou de áreas de necrose - algumas destas com sinais de calcificação. Outras secções, pertencentes sem dúvida a estádios larvários, tinham a cercá-las, em grupos, espessos anéis de tecido fibroso. Cada grupo representava um exemplar inteiro, enovelado. Ovos em grande quantidade, muitos já embrionados, apareciam também nos cortes, dentro de microabscessos ou granulomas. No resto do parênquima, os alvéolos mostravam-se, em grande parte, repletos de histiócitos vacuoliza- 
MORAES, M. A. P.; ARNAUD, M. V. C.: MACEDO, B C. de \& ANGLADA, A. E. - Infeç̄ōo pulmonar fatal por Lagochilascaris sp., provavelmente Lagochilascaris minor Leiper, 1909. Rev. Inst. Med. trop. Săo Paulo 27:46.52, 1985.


Fig. 1 - Lesסes noclulares o difuses na super. ficle de corte do pulmāo, detalho. $3 \times$ Figs. 2 e 3 - Alvéolos pulmonares repletos do
macrofagos vacuolizados; brönquio mostrando
descamaçōo epitelial e deposito de fibrina junto a lámina basal. $200 \mathrm{x}$ dos, leucócitos neutrófilos e fibrina. Coleçōes de linfócitos e plasmócitos eram frequientes em torno dos brónquios, os quais, em adição, apresentavam lesōes severas, como presença de exsudato na luz, grande descamação do epitélio respiratório e espesso depósito de fibrina junto à lâmina basal. Chamava a atençăo a quase total ausência de leucócitos eosinófilos nos tecidos, o que coincidiu, aliás, com a aneosinofilia do sangue periférico.

Os vermes foram identificados como estádios evolutivos de um nematódio do gênero Lagochilascaris, provavelmente Lagochilascaris minor, por sua grande semelhança com as for. 
MORAES, M, A. P.; ARNAUd, M. V. C.; MACEDO, R. C. de \& ANGLADA, A. E. - Infecoão pulmonar fatal por Lagochilascaris sp., provavelmente Lagochilascaris minor Leiper, 1900. Rev. Inst. Med. trop. Sio Paulo 27:46-52, 1985.
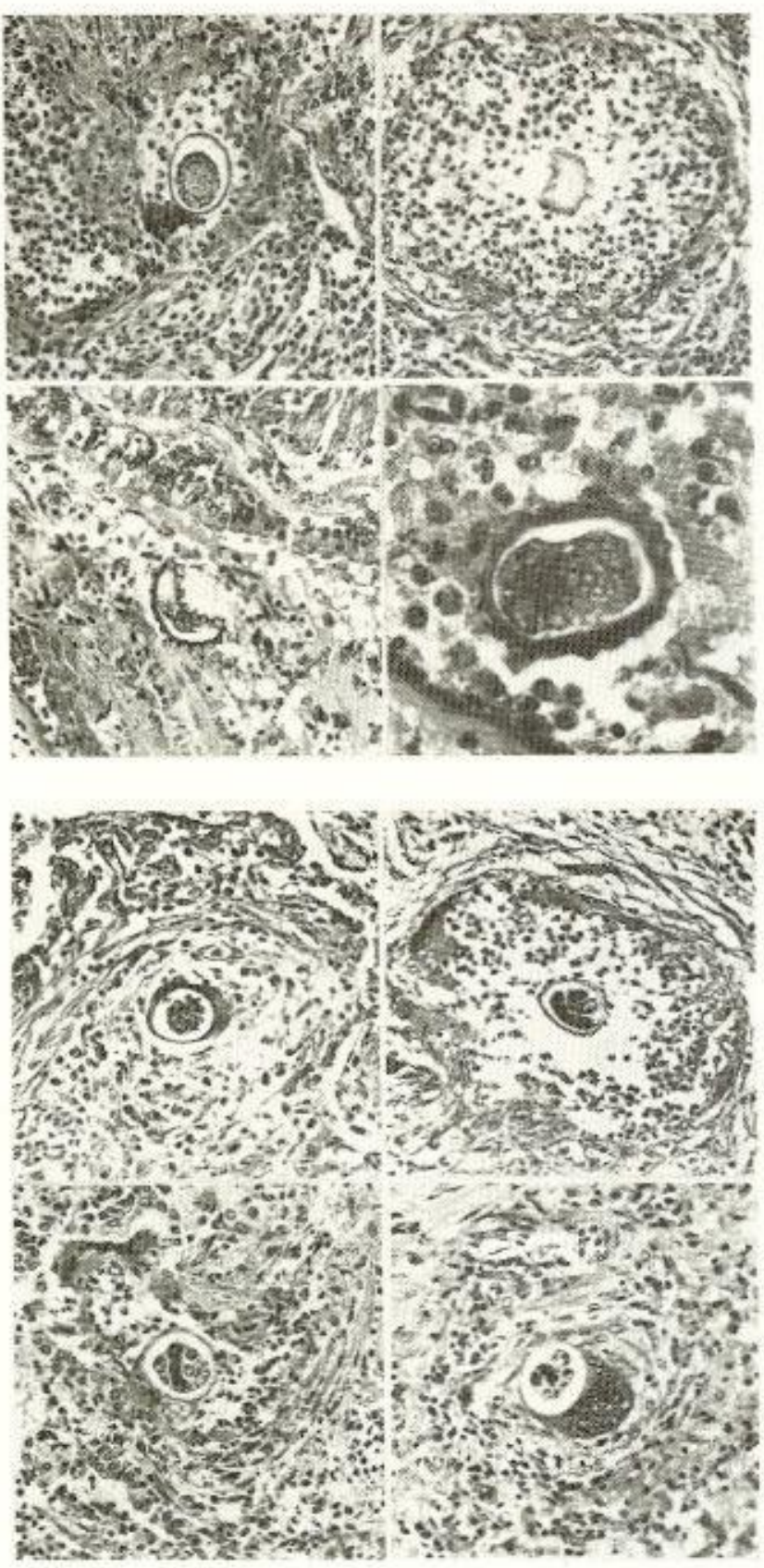

Fig. 4 - Ovos de Lagochilascaris sp. no parênquima pulmonar (em cima) e no interior de brönquios (embaixo). $200 x$ e $500 x$
Fig. 5 - Ovo em segmentaçăo (em cima, a es. querda) e outros jú contendo larvas, provavelmente do 2.0 estriaio. $200 \mathrm{x}$ mas vistas nas lesōes de dois outros casos de lagoquilascariase, observados anteriormente 13. Particular importância teve na identificação o achado de um adulto fêmea - envolvido por grande quantidade de material necrosado, porém ainda perfeito - , em cujas secçóes o útero aparecia cheio de ovos, que exibiam na superfície as reintrâncias caracteristicas do gê- nero. Uma busca cuidadosa nos cortes obtidos dos linfonodos levou à descoberta de algumas larvas do 3 : $^{\circ}$ estádio, envolvidas por tecido fibroso, junto à cápsula do órgão.

\section{COMENTÁRIOS}

Quando, pelo exame histológico, a causa da pneumonite se tornou patente, o material ainda 
MORAES, M. A. P.; ARNAUD, M. V. C.; MACEDO, R. C. de \& ANGLADA, A. E. - Infeçāo pulmonar fatal por Lago. chilascaris sp., provavelmente Lagochilascaris minor Leiper, 1909. Rev. Inst. Med. trop. Săo Paulo 27ః46-52, 1985.

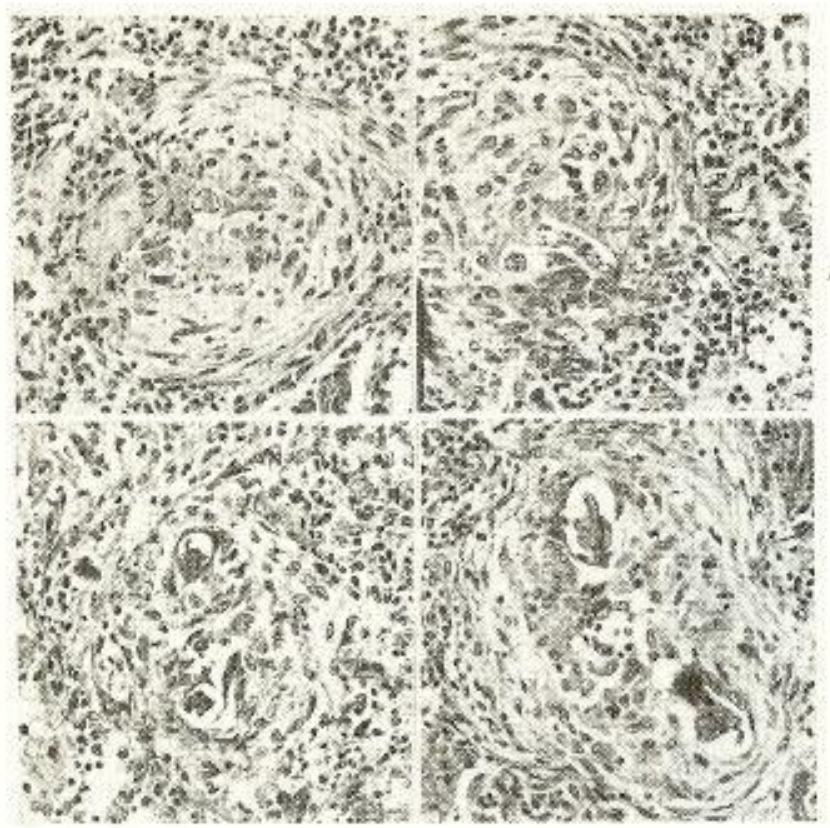

Fig. 6 - Larvas do 2. estádilo, todas clrcundadas por estruturas granulomatasas, $200 x$

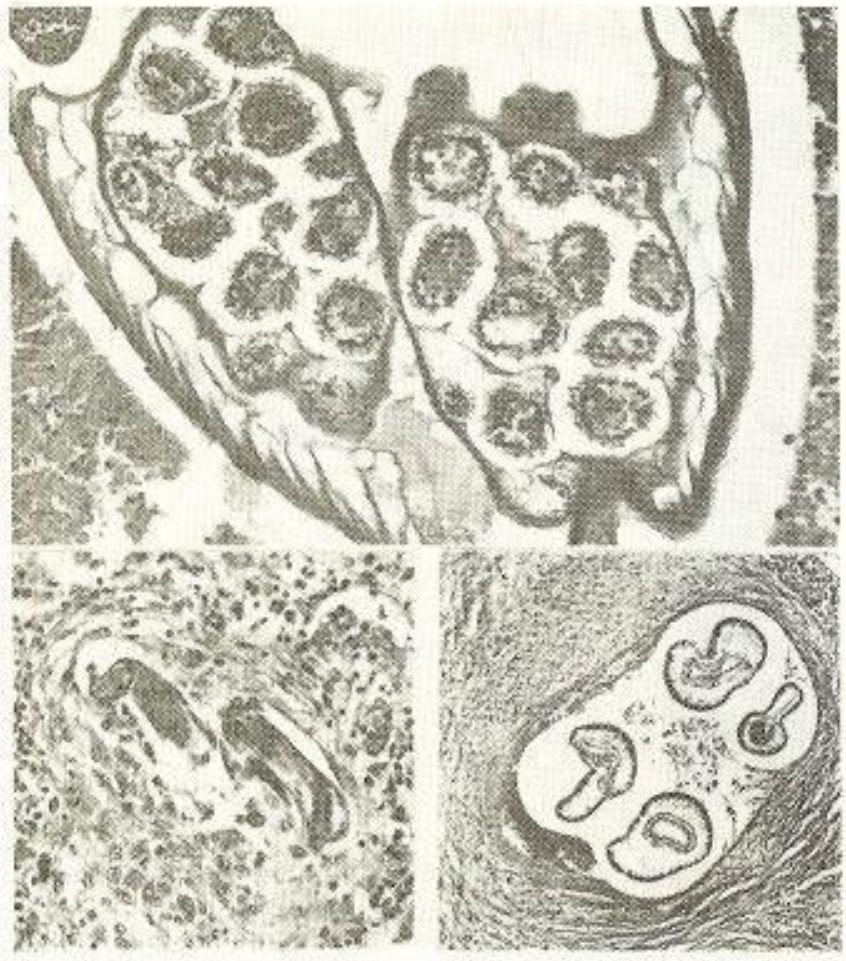

Fig. $\overline{7}$ - Detalhe da 1emea de Lagochilascaris sp. para mostrar o útero cheio de ovos. $200 x$. Em baixo, larvas do $2 .^{\circ}$ e $3 \%^{\circ}$ estálios, $200 x$ e $100 x$

disponível no laboratório - todo ele já fixado em formalina - não mais permitiu a obtençāo de exemplares integros do verme, principalmen. te adultos, que poderiam confirmar em defini. tivo a identificação do parasito. A despeito des. se obstáculo, o achado nos cortes, de secçōes de ovos, com as reintrâncias tipicas do gêne. ro Lagochilascaris, e de uma fèmea - exibindo aletas laterais e o útero repleto de ovos seme. lhantes -, não deixou dúvidas quanto ao gêne- 
MORAES, M. A. P.; ARNAUD, M. V. C.; MACEDO, R. C. de \& ANGLADA, A. E. - Infeção pulmonar fatal por Lago. chilascaris sp., provavelmente Lagochilascaris minor Leiper, 1909. Rev. Inst. Med. trop. São Paulo 27:46-52, 1985.

ro. A possibilidade de tratar-se da espécie $\mathbf{L}$. minor ficou por conta do número de escavaçóes nos ovos encontrados. Em qualquer deles (os menores, que poderiam representar apenas o corte de uma das extremidades, foram desconsiderados) esse número jamais ultrapassou a 25. Como um dado a mais para a identificação, há o fato de ser o Estado do Pará, hoje, uma área reconhecida de lagoquilascaríase, onde, somente nos dois últimos anos, quatro casos novos foram divulgados 9,13 , procedentes de várias localidades. Afora esses quatro, mais dois permanecem ainda inéditos 10 .

Infelizmente, nada se pôde fazer em benefício da doente - embora o tratamento atual para a lagoquilascaríase seja bastante eficaz -, por falta de qualquer conhecimento anterior sobre ser o verme em questão uma causa de pneumonite. Até mesmo a ausência de eosinófilos no sangue contribuía para afastar a suspeita de verminose - no caso, uma possível pneumonite por migração larvária de Ascaris lumbricoides - , suspeita que poderia ter salvo a paciente. O detalhe da falta de eosinófilos, no sangue e nos tecidos, causou espécie, porém uma revisão do assunto mostrou que apenas em um caso de lagoquilascaríase ${ }^{23}$, dentre cin. co nos quais o hemograma foi praticado ou referido, havia eosinofilia; nos demais $11,15,16,22$, os eosinófilos estavam ausentes ou não ultrapassavam os limites da normalidade.

Ao inusitado da localização, deve-se destacar, no caso presente, o encontro de todos os estádios evolutivos do helminto, no órgão atingido. Esse achado apoia firmemente a existência de um ciclo pulmonar, conforme sugerido por SPRENT ${ }^{20}$, para L. minor. Além do mais, tratando-se, ao que tudo indica, de um parasito errático no homem, o mesmo achado mostra que seu desenvolvimento pode se dar em qualquer ponto do sistema respiratório.

\section{SUMMARY}

\section{A fatal case of pulmonary infection with Lagochilascaris sp., probably Lagochilascaris minor Leiper, 1909}

A fatal case of pulmonary infection with Lagochilascaris sp. - probably Lagochilascaris minor - is presented. A 18-year-old girl from Curralinho - State of Pará developed a severe pneumonitis of unknown origin, and died less than three months after the onset of the illness. She was admitted to the Hospital, in BelémPará, on 16 June 1983, with fever, productive cough, dyspnea and, eventually, cyanosis. At that time, she had been sick for at least four or five weeks. A chest X-ray film taken shortIy after admission disclosed extensive bilateral infiltrates, predominantly on the right lung. Acidfast bacilli and fungi, however, could not be demonstrated in the sputum. The leucocyte count 'was low (3.900), with $60 \%$ neutrophils and $40 \%$ lymphocytes. In spite of several therapeutic schedules (no definite cause for the disease could be found) the patient's condition rapidly deteriorated. She persisted with fever, cough, expectoration of thick sputum, dyspnea and cyanosis, but other symptoms also came forth: hoarseness, fatigue, weight loss and labored breathing. On 13 July she developed respiratory insufficiency and died. At autopsy, the lungs appeared distended with numerous areas of consolidation; the cut surface, when exposed, revealed disseminated foci, both nodular and aiffuse, of granulomatous and exsudative inflammation. Microscopicalliy, sections of eggs and round worms were found in the preparations, always surrounded by granulomas or lar. ge areas of necrotic tissue. The worms were recognized as evolutive stages - larvae, adult males and a gravid female - of a nematode belonging to the genus Lagochilascaris, probably Lagochilascaris minor. The identification was based, mainly, on the aspect of the eggs, which exhibited the irregular-shaped, saucerlike depressions or pits, characteristic of the genus. The female worm had lateral alae and the uterus full with similar eggs. In all 25 cases of human lagochilascariasis so far described, the Iocation of the lesions was in the region of neck, ear, mastoid process, orbit, paranasal sinuses and retropharingeal tissues. For the first time, the present case, a member of the genus Lagochilascaris is referred to in a different site of the host. Besides that, the finding of eggs, larvae and adult worms in the lung tissues strongly suggests the existence of a pulmonary cycle in human lagochilascariasis.

\section{REFERENCIAS BIBLIOGRAFICAS}

1. ARTIGAS, P. T.; ARAƯJO, P.; ROMITI, N. \& RUIVO, M. - Sobre um caso de parasitismo humano por Lagochilascaris minor Leiper, 1909, no Estado de São Paulo, Brasil. Rev. Inst. Med. trop. São Paulo 10: $78-83,1968$. 
MORAES, M. A. P.; ARNAUD, M. V. C.; MACEDO, R. C. de \& ANGLADA, A. E. - Infecção pulmonar fatal por Lagochilascaris sp., provavelmente Lagochilascaris minor Leiper, 1909. Rev. Inst. Med. trop. São Paulo 27:46-52, 1985.

2. BORGO, A. V.; ANDRADE, A. L. S.; PEDROSA, R. B.; BARBOSA, W. \& KOMMA, M. D. - Infecção por Lagochilasearis minor - apresentação de caso. Resum. Temas Livres XIV Gongr. Soe. Bras. Med. Trop. e III Congr. Soc. Bras. Parasit. (João Pessoa, Paraíba, Fev. 19-23, 1978), pág. 391.

3. BRENES, M. R. R. \& BRENES, A. F. - Lagochilascariasis humana en Costa Rica. Progr. Gen. y Resum. Trab. Congr. Latinoam. y Nac. Microbiol. (Ciudad Universitaria, Costa Rica, Dec. 10-17, 1961), pág. 35.

4. BRUIJNING, C. F. A. - Note on Lagochilascaris minor Leiper, 1909. Docum. Med. Geog. et Trop. 9: 173-175, 1957.

5. CAMPOS, D. M. B.; KOMMA, M. D.; SANTOS, M. A. Q. \& PITALUGA, W. M. N. V. - Lagochilascaris minor Leiper, 1909; casos diagnosticados no Departamento de Parasitologia. Resum. Temas Livres VIII Congr. Soc. Bras. Parasit. $\theta$ VI Congr. Feder. Latinoam. Parasitólogos (São Paulo, São Paulo, Set. 4-8, 1983).

6. CHIEEFI, P. P.; FRUCCHI, H.; PROENÇA, N. G.: PEREIRA, W. A. \& PASCHOALOTTI, M. A. - Infecção cutânea por Lagochilascaris minor: tratamento e cura rápida pelo levamisol. An. Brasil. Dermatol. 56: $141-144,1981$.

7. CORREA, M. O. A.; HYAKUTAKE, S.; BRANDI, A. J. \& MONTEIRO, C. G. - Novo caso de parasitismo humano por Lagochilascaris minor Leiper, 1909. Rev. Inst. Adolfo Lutz 38: 59-65, 1978.

8. DRAPER, J. W. - Infections with Lagochilascaris minor. Brit. Med. J. 1 (5335): 931-932, 1963.

9. FRAIHA, H.; ROCHA, M. P. C.; ARAÚJO, O. J.; BARROS. V. L. R. S.; PRIMO, A.; MORAES, M. A. P.; CONCEIÇÃO, J. R. \& OLIVEIRA, J. E. G. Infecção humana por Lagochilascaris minor Leiper, 1909 (Nematoda, Ascarididae). Registro de três novos casos, e formulação de nova hipótese para o mecanismo de infecção. Resum. Temas Livres vIrr Congr. Soc. Bras. Parasit. e VI Congr. Feder. Latinoam. Parasitólogos (São Paulo, São Paulo, Set. 4-8, 1983).

10. FRATHA, H. - Informação pessoal.

11. LEÄO, R. N. Q.; LEĀO FILHO, J.; DIAS, L. B. \& CALHEIROS, L. B. - Infecção humana pelo Lagochi. lascaris minor Lsiper, 1909; registro de um caso observado no Estado do Pará (Brasil). Rev. Inst. Med. trop. São Paulo 20: 300-306, 1978.
12. LEIPER, R. T. - A new nematode worm from Trinidad: Lagochilascaris minor sp. n. Proc. Zool. Soc. London, Abstract 74: 35-36, 1909.

13. MORAES, M. A. P.; ARNAUD, M. V. C. \& LIMA, P. E. - Novos casos de infecção humana por Lago. chilascaris minor Leiper, 1909, encontrados no Estado do Pará, Brasil. Rev. Inst. Med. trop. São Paulo 25: 139-146, 1983.

14. NASSY, E. A. - Comunicaçăo ao Congresso LatinoAmericano de Otolaringologia, Caracas, Fev. 1954.

15. OOSTBURG, B. F. J. \& VARMA, A. A. O. - Lago. chilascaris minor infection in Surinam: report of a case. Am. J. Trop. Med. \& Hyg. 17: 548-550, 1968.

16. OOSTBURG, B. F. J. - Thiabendazole therapy of Lagochilascaris minor in Surinam: report of a case. Am. J. Trop. Med. \& Hyg. 20: 580-583, 1971.

17. PAWAN, J. L. - A case of infection with Lagochilascaris minor (Leiper). Ann. Trop. Med. Parasit. 20: 201-202, 1925.

18. PAWAN, J. L. - Another case of infection with Lagochilascaris minor (Leiper). Ann. Trop. Med. Parasit. 21: $45-46,1927$.

19. SANTOS, M. A. Q. - Lagochilascaris minor, $1909 \mathrm{em}$ abscesso dentário, no Estado de Goiás. Resum. Temas Livres VI Congr. Soc. Bras. Parasit. (Belo Horizonte, Minas Gerais, Fev. 15-18, 1981).

20. SPRENT, J. F. A. - Speriation and development in the genus Lagochilascaris. Parasitology 62: 71-112, 1971 .

21. VERHAGEN, A. - Een geval van midden-oorontsteking veroorzaakt door een worm. Neder. Tijdschr. v. Geneesk. 65: 3488-3489, 1921.

22. VOLCAN G., G. S.; OCHOA, F. R.; MEDRANO, C. E. \& VALERA, Y. - Lagochilasearis minor infection in Venezuela: report of a case. Am. J. Trop. Med. \& Hyg. 31: 1111-1113, 1982

23. WINCKEL, W. E. F. \& TREURNIET, A. E. - Infestation with Lagochilascaris minor (Leiper) in man. Doc. Med. Geogr. et Trop. 8: 23-28, 1956.

Recebido para publicação em 27/3/1984. 